\title{
Effects of Glucose Infusion on Leucine Transamination and Oxidation in the Ovine Fetus
}

\author{
EDWARD A. LIECHTY, SCOTT C. DENNE, JAMES A. LEMONS, AND C. LAWRENCE KIEN \\ Department of Pediatrics, Indiana University School of Medicine, Indianapolis, Indiana 46202 and Department \\ of Pediatrics, The Ohio State University School of Medicine, Columbus, Ohio 43205
}

\begin{abstract}
During fasting of the ewe, the rate of amino acid oxidation by the ovine fetus increases substantially. We hypothesized that the increase in amino acid oxidation derived mainly from reduced protein synthesis. We further hypothesized that fetal glucose supplementation would result in diminished amino acid oxidation. To test these hypotheses, nine ovine fetuses were infused with $\left[{ }^{15} \mathrm{~N}, 1-\right.$ ${ }^{13}$ Clleucine to determine the rates of leucine appearance and disposal. Simultaneously, the fetal uptake of leucine was determined. Animals were studied in the fed and fasted state. After baseline measurements, glucose was infused into the fetal inferior vena cava at a rate estimated to match the fetal glucose uptake. Results of these studies indicate that leucine nitrogen flux, leucine carbon flux and fetal leucine uptake were constant. Leucine oxidation was increased by $50 \%$ in the fasted state $(6.3$ versus $13.4 \mu \mathrm{mol} /$ $\mathrm{min})$; glucose infusion resulted in a $25 \%$ decline in oxidation (to $10.4 \mu \mathrm{mol} / \mathrm{min}$ ) in the fasted state, but had no effect in the fed state. Mean leucine umbilical uptake during fasting was $9.3 \mu \mathrm{mol} / \mathrm{min}, 4.1 \mu \mathrm{mol} / \mathrm{min}$ less than leucine oxidation. These data suggest that leucine (and potentially other amino acids) may be in negative balance during maternal fasting, and can be spared by supplementation of the fetus with exogenous glucose. (Pediatr Res 30: 423-429, 1991)
\end{abstract}

\section{Abbreviations}

KIC, $\alpha$-ketoisocaproate

GC/MS, gas chromatograph/mass spectrometry

BCAA, branched chain amino acid

ANOVA, analysis of variance

The ovine fetus responds to maternal food deprivation by becoming hypoglycemic and hypoinsulinemic (1). The high rate of fetal uptake of amino acids continues unabated, however, and amino acid oxidation increases substantially (2). Thus, the ovine fetus, studied when the ewe is fed and again when chronically fasted, represents a unique model in which exogenous glucose supply is severely but not completely curtailed, yet amino acid intake remains constant. Our previous data, based upon fetal hindlimb arteriovenous differences for the BCAA, suggested that protein accretion diminished, but net balance remained positive (3). These observations indicated that amino acids from the ewe were being redirected toward oxidation rather than growth, with no net loss of fetal protein.

We hypothesized that maternal food deprivation would result

Received October 24, 1990; accepted July 3, 1991.

Correspondence: Edward Liechty, Riley R-208, 702 Barnhill Drive, Indianapolis, In 46202-5210.

Supported by PHS Grants RO1-HD19089, KO4-HD00865, and PH60-DK20542 . in increased fetal oxidation of amino acids, a diminished rate of protein synthesis, and no significant change in the rate of protein degradation. To further test this hypothesis, a labeled amino acid was used as a tracer to allow the quantitative estimates of fetal protein breakdown, protein synthesis, and oxidation. Coupled with measurements of fetal uptake, all parameters of the movement of a given amino acid through fetal plasma could then be observed. Controlled perturbations of the physiologic state of the fetus were then initiated with the aim of determining the effect of substrate supply on protein synthesis, breakdown, and amino acid oxidation.

We have chosen leucine as a representative amino acid to study fetal protein kinetics. The fetal uptake of this essential amino acid even under normal conditions is large relative to its carcass accretion rate (4), implying a significant contribution of this amino acid to oxidative or other pathways. In addition, leucine has been used extensively for modeling protein kinetics in postnatal animals.

The aim of the present study was to investigate how the ovine fetus adapts its amino acid metabolism to augmentation of glucose intake. We hypothesized that augmentation of glucose supply to the fetus would result in diminished leucine oxidation. To study this question, the net rates of fetal uptake of leucine and rates of nonoxidative leucine disposal, oxidation, and leucine derived from protein breakdown were determined in the fed and fasted state. During each study a series of baseline determinations were made, followed by a second series of determinations during exogenous glucose infusion into the fetus. This study design resulted in a wide range of fetal arterial glucose concentrations, total fetal glucose intakes, and insulin concentrations, but consistent leucine intakes.

\section{MATERIALS AND METHODS}

Ewes of 115-120 d gestation were used for this study. Animal care was in strict compliance with National Institutes of Health guidelines, and the study protocols were approved by the Animal Care Review Committee.

Surgical procedures were performed aseptically under general anesthesia. Anesthesia was accomplished by i.v. pentobarbital and halothane inhalation. Catheters were placed in the common umbilical vein, fetal aorta, and inferior vena cava (two catheters). Catheters were exteriorized and irrigated daily with $0.9 \%$ saline $\mathrm{wt} / \mathrm{vol}$, containing $30 \mathrm{U}$ heparin per $\mathrm{mL}$. All ewes consumed ad libitum a diet consisting of hay and pelletized alfalfa and had constant access to water.

Study design. Animals were allowed to recover from surgery for a minimum of $5 \mathrm{~d}$, and were feeding ad libitum before the initial studies were performed. Access to feed was continued throughout the performance of the fed study. On the day of the study, baseline samples were obtained for isotopic enrichment of $\mathrm{CO}_{2}$, leucine, and KIC. An infusion of $\mathrm{L}-\left[{ }^{15} \mathrm{~N}, \mathrm{l}^{13} \mathrm{C}\right]$ leucine $(99 \%$; 


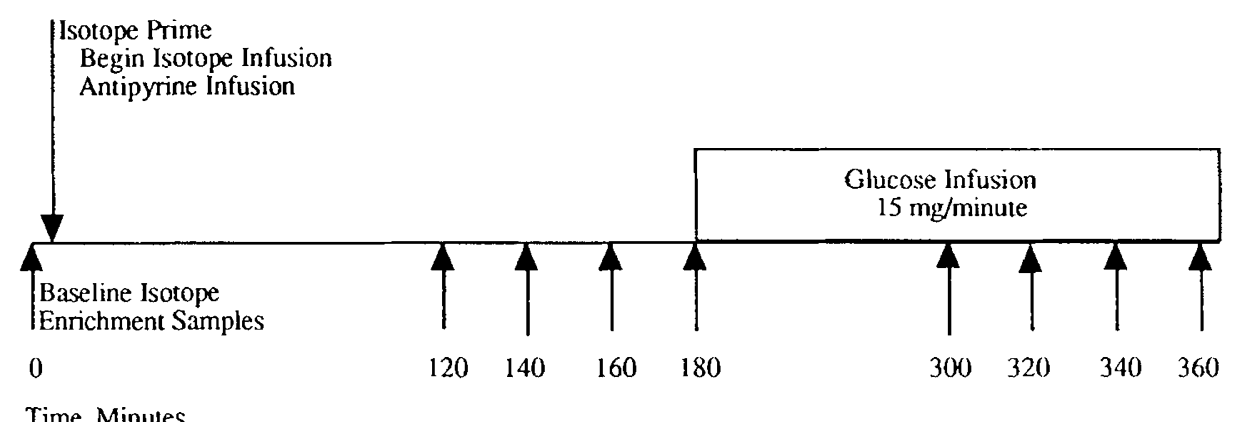

Fig. 1. Diagram of the experimental protocol. Nine animals were studied in fed and fasted states. Study protocols were identified for each state.

Tracer Technologies, Somerville, $\mathrm{MA}^{1}$ ) was begun into the fetal inferior vena cava. A priming dose consisting of $60 \mathrm{~min}$ of infusate was given as a bolus, followed by a continuous infusion at a rate of $1.5 \mu \mathrm{mol} / \mathrm{min}$. After a 120 -min equilibration period, four sets of samples were obtained at 20 -min intervals constituting the preglucose infusion study. A continuous infusion of glucose [12.88 $\pm 2.45(\mathrm{SD}) \mathrm{mg} / \mathrm{min}]$ was then begun into the inferior vena cava. This rate of glucose infusion was chosen to duplicate the average fetal glucose uptake. After a second 120min equilibration period, four additional sets of samples were obtained at 20 -min intervals, constituting the during glucose infusion study (Fig. 1).

The ewe was then removed from access to food for $5 \mathrm{~d}$ and the studies repeated, constituting the fasted studies. The actual duration of fasting was $104 \pm 12$ (SD) $h$, which resulted in a loss of $3.8 \pm 0.9 \mathrm{~kg}$ of body mass by the ewe. Only animals that had completed fed and fasted studies were included in the data analysis. Therefore, each animal had four sets of data obtained. Nine animals completed the study and constitute the basis for this report.

Analytical methods. Glucose was analyzed in whole blood by the glucose oxidase method (Boehringer-Mannheim Kit no. 189197).

Whole blood and tracer infusate leucine concentrations were determined by standard ion exchange chromatography methodology, using a Beckman 6300 automated amino acid analyzer (Beckman Instruments, Inc., San Ramon, CA). Intraassay coefficient of variation was $<3 \%$.

KIC was determined in whole blood after derivatization with ortho-phenylenediamine (5). The derivative is separated by reversed phase HPLC followed by fluorescence detection. The intraassay coefficient of variation was $7 \%$ for $\mathrm{KIC}$.

Insulin concentrations in plasma were determined in duplicate by a double antibody RIA, with sheep insulin used to construct the standard curve. Intraassay coefficient of variation was $10 \%$.

The whole blood $\mathrm{PCO}_{2}$ and $\mathrm{pH}$ were determined using an Instrumentation Laboratories 1301 Arterial Blood Gas instrument. Whole blood $\mathrm{CO}_{2}$ content was then calculated by the Henderson-Hasselbach equation (corrected to $39.5^{\circ} \mathrm{C}$ ) (6).

To determine whole blood $\mathrm{CO}_{2}$ enrichment, $\mathrm{CO}_{2}$ was first isolated from whole blood by acid liberation and cryogenic distillation (7). The ${ }^{13} \mathrm{C} /{ }^{12} \mathrm{C}$ ratio was then measured on a Finnigan MAT (San Jose, CA) Delta $\mathrm{E}$ isotope ratio mass spectrometer. Each ratio was related to the standard, Peedee Belemnite, for determining the atoms percent ${ }^{13} \mathrm{C}$. Atoms percent excess (APE) was calculated as sample atoms percent - baseline atoms percent.

Leucine isotopic enrichment was determined in whole blood and plasma by formation of the $\mathrm{N}$-acetyl- $n$-propyl derivative (8). This derivative was injected into a Finnigan $4500 \mathrm{GC} / \mathrm{MS}$ with

${ }^{1} \mathrm{~L}-\left[{ }^{15} \mathrm{~N}, 1-{ }^{13} \mathrm{C}\right]$ leucine was obtained from Tracer Technologies, Somerville, MA Manufacturer's specifications were $>99 \% \mathrm{~L}$ form, as determined on an optically active column, and $>99 \%$ enriched for both ${ }^{13} \mathrm{C} /{ }^{12} \mathrm{C}$ at position 1 and ${ }^{15} \mathrm{~N} /{ }^{14} \mathrm{~N}$. These specifications were verified by the manufacturer; data are available on request. methane chemical ionization, and selected ion monitoring of ions at $\mathrm{m} / \mathrm{e} 216,217$, and 218 . The ratio of double-labeled to unlabeled leucine was calculated as integrated [area of 218]/[area of 216], for baseline $\left(r_{N}\right)$ and plateau ( $\left.r_{m}\right)$ samples. Moles percent excess (MPE) was calculated in the following manner (9):

$$
\text { MPE }=\frac{\left(r_{m}-r_{N}\right)}{\left(r_{m}-r_{N}+1\right)} \cdot 100
$$

The contribution of mono-labeled species to the $\mathrm{M}+2$ signal was estimated as the ratio of $217 / 216$ for the baseline sample. Plateau M+2 enrichments were corrected downward by this percentage. Baseline and all plateau samples for a single animal were analyzed on the same day; standard isotope dilution curves were not used to estimate MPE.

Isotopic enrichment of KIC was determined by electron impact GC/MS. The quinoxalinol-trimethylsilyl derivative was prepared and analyzed by capillary GC/MS (10). Selected ion monitoring of ions at m/e 232 and 233 was performed. The ratio of labeled to unlabeled $\mathrm{KIC}$ was calculated as integrated [area of 233]/[area of 232] for baseline $\left(\mathrm{r}_{\mathrm{N}}\right)$, and plateau $\left(\mathrm{r}_{\mathrm{m}}\right)$ samples. Moles percent excess (MPE) was calculated using equation 1; standard isotope dilution curves were not used to estimate MPE.

Antipyrine was determined in whole blood by reversed phase HPLC, with phenacetin as internal standard and UV monitoring at $254 \mathrm{~nm}$.

Calculations. Umbilical blood flow was calculated by the steady state antipyrine diffusion method (11). The fetal umbilical uptakes of leucine, KIC, and glucose were calculated as the product of the umbilical arteriovenous concentration difference and the umbilical blood flow. Total fetal glucose intake was calculated as the sum of umbilical glucose uptake and glucose infusion.

Model for leucine flux. The model of leucine flux in the fetus used is an adaptation of that described by Mathews et al. (12). This model allows the simultaneous determination of leucine carbon and nitrogen flux, as well as oxidative leucine disposal.

When infusing $\left[{ }^{15} \mathrm{~N}, \mathrm{l}^{13} \mathrm{C}\right]$ leucine into the fetus, the rate of disappearance of the nitrogen label $\left(\mathrm{Rd}_{\mathrm{N}}\right)$ is via transamination of leucine to $\mathrm{KIC}\left(\mathrm{X}_{\mathrm{O}}\right)$, and by nonoxidative leucine disposal (presumably protein synthesis, $S$ ). The rate of appearance of the nitrogen label $\left(\mathrm{Ra}_{N}\right)$ is via fetal uptake of leucine, KIC reaminated to leucine $\left(\mathrm{X}_{\mathrm{N}}\right)$, and leucine appearing from protein breakdown (B). (Fig. 2). Therefore,

$$
\operatorname{Rd}_{N}=S+X_{O}
$$

and

$$
\mathrm{Ra}_{\mathrm{N}}=\text { Fetal umbilical uptake }+\mathrm{B}+\mathrm{X}_{\mathrm{N}}
$$

At steady state, $R \mathrm{a}_{\mathrm{N}}=\mathrm{Rd}_{\mathrm{N}}$, and defines fetal leucine nitrogen turnover. Because the transamination reactions are reversible, rates of leucine flux will be greater when calculated from the dilution of a nitrogen tracer than when calculated from a carbon tracer. 


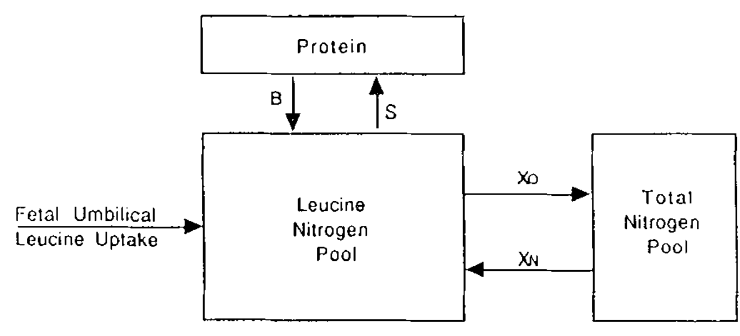

Fig. 2. The model for determination of leucine nitrogen kinetics in the ovine fetus during infusion of $\left[{ }^{15} \mathrm{~N}, 1-{ }^{13} \mathrm{C}\right]$ leucine into the fetal inferior vena cava. Leucine nitrogen enters the fetal plasma pool through fetal umbilical uptake, from protein breakdown $(B)$, and from reamination of KIC to leucine $(X N)$. Leucine nitrogen leaves the fetal pool through protein synthesis $(S)$ and deamination of leucine to $\mathrm{KIC}(X O)$.

Leucine nitrogen turnover was calculated as:

$$
R a_{N}=R d_{N}=\left(\frac{E_{\text {inf }}}{M P E_{\text {sample }}}-1\right) \cdot \text { Inf rate }
$$

where $R a_{N}=$ rate of appearance of leucine nitrogen, $R d_{N}=$ rate of disappearance of leucine nitrogen, $\mathrm{E}_{\mathrm{inf}}=$ infusate enrichment $(99 \%), \mathrm{MPE}_{\text {sample }}=$ sample moles percent excess doubly labeled leucine, and Inf rate $=$ tracer infusion rate $(\mu \mathrm{mol} / \mathrm{min})$. The corrected infusate leucine concentration determined by ion exchange chromatography was used to calculate the infusion rate.

The loss of the leucine amino nitrogen is reversible; therefore, reamination of the tracer molecule is possible, resulting in an $M+1$ species. The rate of disappearance of the leucine carbon label $\left(\mathrm{Rd}_{C}\right)$ is via the irreversible decarboxylation step or utilization for protein synthesis. The rate of appearance of leucine carbon $\left(\mathrm{Ra}_{C}\right)$ into plasma is from protein breakdown and by fetal uptake of leucine (Fig. 3). Therefore,

$$
\mathrm{Ra}_{\mathrm{C}}=\text { Fetal umbilical uptake }+\mathrm{B}
$$

and

$$
\operatorname{Rd}_{\mathrm{C}}=\mathrm{S}+\mathrm{Ox}
$$

where $\mathrm{Ox}=$ oxidative leucine disposal

The plasma enrichment of KIC has been shown to be a representative tracer of the intracellular leucine enrichment (13). Leucine carbon flux was calculated as:

$$
\operatorname{Ra}_{C}=\operatorname{Rd}_{C}=\left(\frac{E_{\text {inf }}}{M P E_{\text {sample }}}-1\right) \cdot \text { Inf rate }
$$

where $\mathrm{MPE}_{\text {samplc }}=$ sample moles percent excess for KIC. Leucine oxidation was calculated as:

$$
\mathrm{Ox}=\frac{\left[\left(\mathrm{a}^{13} \mathrm{CO}_{2} \cdot \mathrm{aCO}_{2}\right)-\left(\mathrm{uv}^{13} \mathrm{CO}_{2} \cdot \mathrm{uvCO}\right)\right]}{\mathrm{MPE} \mathrm{KIC}_{\mathrm{C}}} \cdot \mathrm{UmBF}
$$

where $\mathrm{aCO}_{2}=$ fetal arterial $\mathrm{CO}_{2}$ content, $\mathrm{a}^{13} \mathrm{CO}_{2}=$ fetal arterial $\mathrm{CO}_{2}$ enrichment (APE), uvCO $\mathrm{CO}_{2}=$ umbilical venous $\mathrm{CO}_{2}$ content, $\mathrm{uv}^{13} \mathrm{CO}_{2}=$ umbilical venous $\mathrm{CO}_{2}$ enrichment $(\mathrm{APE}), \mathrm{MPE} \mathrm{KIC}_{\mathrm{C}}=$ KIC moles percent excess, and UmBF $=$ umbilical blood flow.

No correction for $\mathrm{CO}_{2}$ fixation was made, inasmuch as Van Veen et al. (14) have demonstrated no appreciable label fixation during fetal infusion of $\mathrm{NaH}^{14} \mathrm{CO}_{2}$.

Leucine derived from protein breakdown (B) was calculated as:

$$
\mathrm{B}=\mathrm{Ra}_{\mathrm{C}}-\text { Fetal umbilical uptake }
$$

Nonoxidative leucine disposal (i.e. used for protein synthesis), $\mathrm{S}$, was calculated as:

$$
\mathrm{S}=\mathrm{Rd}_{\mathrm{C}}-\mathrm{Ox}
$$

Subtraction of equation 5 from equation 3 yields the equation for $\mathrm{KIC}$ transamination to leucine, $\mathrm{X}_{\mathrm{N}}$ :

$$
X_{N}=R a_{N}-R a_{C}
$$

By subtraction of equation 6 from equation 2 , and by substituting $X_{N}$ for $\left(\mathrm{Ra}_{\mathrm{N}}-\mathrm{Ra}_{\mathrm{C}}\right)$, leucine transamination to $\mathrm{KIC}\left(\mathrm{X}_{\mathrm{O}}\right)$ is the sum of oxidation and $\mathrm{KIC}$ reaminated to leucine:

$$
\mathrm{X}_{\mathrm{O}}=\mathrm{Ox}+\mathrm{X}_{\mathrm{N}}
$$

It is possible that tracer was lost to the maternal circulation, resulting in an overestimate of nonoxidative disposal. To correct for this, it would be necessary to determine this rate of tracer loss, subtracting it from the tracer infusion rate. This would require determining the whole blood leucine enrichment and concentrations across the umbilical circulation. We were unable to consistently measure an umbilical arteriovenous difference of labeled amino acid in whole blood, because the analytical precision was not sufficient to measure this small arteriovenous difference. Therefore, we did not correct our infusion rate for potential transplacental loss, which we believe to be small. This may have resulted in a slight overestimation of the synthesis rate.

Previous work in humans has shown that the prevailing physiologic state of the subject can affect the baseline enrichment of $\mathrm{CO}_{2}$ that is produced (15). During glucose infusion, therefore, the $\mathrm{CO}_{2}$ enrichment rises, even in the absence of tracer infusion. To evaluate this possibility, we infused three animals with glucose

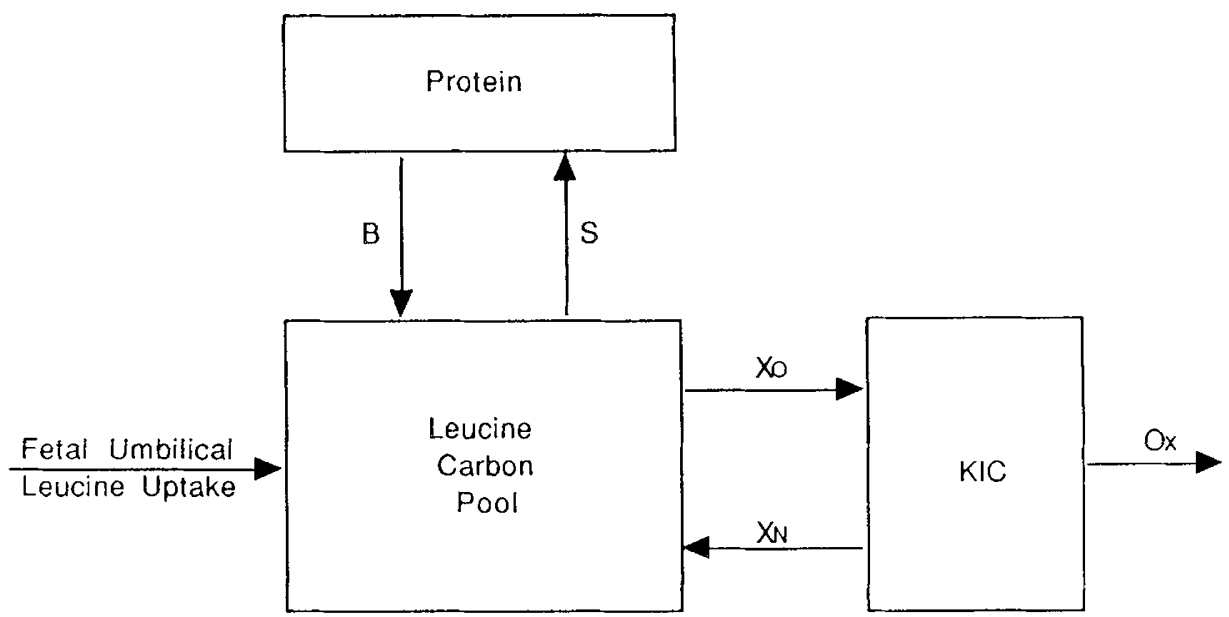

Fig. 3. The model for determination of leucine carbon kinetics in the ovine fetus during infusion of $\left[{ }^{15} \mathrm{~N}, 1-{ }^{13} \mathrm{C}\right]$ leucine into the fetal inferior vena cava. Leucine carbon enters the fetal plasma pool through fetal umbilical uptake and from protein breakdown $(B)$. Leucine carbon leaves the fetal pool through protein synthesis $(S)$ and oxidation of $\mathrm{KIC}(O x)$. This model does not account for the potential influx of unlabeled KIC that may be derived from maternal leucine, transaminated in the placenta, and may subsequently enter directly into fetal plasma. 
at an equivalent rate to those in the study and determined the $\mathrm{CO}_{2}$ enrichment. In these animals the $\mathrm{CO}_{2}$ enrichment during infusion was not significantly different from the preinfusion samples.

Statistics. Each animal was studied in four states: 1) fed, preglucose; 2) fed, during glucose; 3) fasted, preglucose; and 4) fasted, during glucose. Samples from within each state for the same animal were pooled. Carbon flux data was obtained in all nine animals. Nitrogen flux data was obtained from eight animals, and leucine oxidation data obtained from five animals. Three-way ANOVA was used for data analysis. Experimental factors were fed/fast and preglucose/during glucose. Interanimal variation was controlled for as a random factor. A priori hypotheses (Fed, preglucose versus fasted, preglucose; fed, preglucose versus fed, during glucose; and fasted, preglucose versus fasted, during glucose) were tested by three-way ANOVA and single degree of freedom cell means orthogonal contrasts (16), with $p<0.05$ as the level of significance (SuperANOVA; Abacus Concepts, Berkeley, CA). Correlations were analyzed by simple regression.

Except where noted, data were not normalized to fetal weight inasmuch as the fetal weight at the time of the fed studies is unknown. The mean fetal weight at the time of sacrifice (immediately after the fasted study) was $2.98 \pm 0.48$ (SD) $\mathrm{kg}$.

\section{RESULTS}

Glucose. Fasting of the ewe resulted in a significant decline in fetal whole blood arterial glucose concentration and fetal glucose uptake (Table 1). These data are consistent with previous studies of ovine fetal glucose concentration and uptake. During infusion of glucose, arterial glucose rose, and fetal glucose uptake fell. In the fasted ewes, fetal umbilical glucose uptake during glucose infusion was not different from 0 . In contrast, significant fetal umbilical glucose uptake continued during glucose infusion in the fed state. There was, therefore, a significant difference in total fetal glucose intake (defined as fetal umbilical glucose uptake + exogenous glucose infused, $\mathrm{mg} / \mathrm{min}$ ) between the two study states (fed and fasted).

Insulin. The mean insulin concentration was greater in the fed state versus the fasted $(p<0.05)$ (Table 1$)$. The increment in insulin concentration with glucose infusion was statistically significant only during the fasted state.

Leucine, KIC concentraiton, and uptake. The leucine concentration in fetal plasma increased substantially with fasting, from $146 \pm 13$ to $265 \pm 30 \mu \mathrm{M}, p<0.05$. Leucine concentration did not change during glucose infusion. The change in fetal arteral KIC concentration was qualitatively similar to leucine, increasing during the fasted state $(21 \pm 1.0$ to $37 \pm 1.5 \mu \mathrm{M}, p<0.05)$. The fetal uptake of leucine did not change from fed to fasted, nor with glucose infusion. The mean fetal uptake of KIC was equal to $5 \%$ of total leucine carbon skeleton during the fed state and
$10 \%$ during fasting. The uptake of KIC did increase significantly during fasting, whereas that of leucine did not.

Leucine kinetics. The isotopic enrichments achieved in this study are shown in Figure 4 . The parameters of leucine carbon flux calculated from these enrichments are shown in Table 2. As can be seen, carbon flux remained relatively constant. As noted above, fetal leucine uptake was also unchanged, so estimated rates of leucine appearance from protein breakdown were unchanged. Oxidation increased significantly during fasting. Leucine oxidation was, when normalized to fetal body mass, directly correlated to the fetal arterial leucine concentration (Fig. 5). Glucose infusion resulted in a fall in oxidation during the fasted state, but had no effect during the fed state. The increase in oxidation, coupled with constant flux and fetal uptake, resulted in a decline in estimated rates of leucine disposal for protein synthesis during the fasted state.

It is possible that there is significant fetal uptake of unlabeled KIC from the maternal circulation. To investigate this possibility, we analyzed whole blood samples obtained simultaneously from the umbilical artery and vein for KIC enrichment. The results, given in Table 3 , show that the umbilical venous enrichment is not significantly different from the arterial enrichment. This suggests that there is not a significant dilution of the fetal KIC pool by unlabeled KIC derived from the maternal pool.

Leucine nitrogen flux and deamination rates were similarly unaffected by fed and fasting states and by infusion of glucose (Table 4). The data demonstrate that, under physiologic conditions in the fetus, the reamination of KIC to leucine contributes substantially to leucine nitrogen flux. During fasting, there is a significant decline in the reamination rate consistent with the simultaneous increase in leucine oxidation rate.

\section{DISCUSSION}

Protein accretion in the ovine fetus represents a balance between protein synthesis and breakdown, fetal amino acid uptake, and amino acid oxidation. All four processes occur continuously. Under normal circumstances the ovine fetus is more reliant upon amino acid oxidation as a source of metabolizable energy than is characteristic of postnatal life, with up to $25 \%$ of total amino acid nitrogen uptake being excreted as urea. During fasting of the ewe, fetal amino acid uptake remains unchanged, whereas $50 \%$ of the transplacentally acquired amino acids are oxidized and converted to urea (2). It is, therefore, important to understand the mechanisms that modulate flux of amino acids through synthetic versus oxidative pathways.

The goal of this study was to gain insight into the importance of substrate supply (glucose, amino acids) in modulating fetal leucine flux. In particular, we were interested in whether supplementation of the fetal glucose supply would affect and possibly reverse the increased amino acid oxidation known to occur during fasting-induced hypoglycemia.

Table 1. Changes in glucose and insulin parameters $(n=9 \text { animals, mean } \pm S E M)^{*}$

\begin{tabular}{|c|c|c|c|c|}
\hline & \multicolumn{2}{|c|}{ Fed } & \multicolumn{2}{|c|}{ Fasted } \\
\hline & Preglucose & During glucose & Preglucose & During glucose \\
\hline Glucose (mM) & $1.08 \pm 0.11$ & $1.31 \pm 0.12 \dagger$ & $0.683 \pm 0.07 \pm$ & $1.12 \pm 0.14 \S$ \\
\hline Fetal umbilical glucose uptake $(\mu \mathrm{mol} / \mathrm{min})$ & $90.0 \pm 11$ & $47.1 \pm 15 \dagger$ & $65.0 \pm 7.7 \ddagger$ & $-4.4 \pm 14 \S$ \\
\hline Total glucose intake $(\mu \mathrm{mol} / \mathrm{min})$ & $90.0 \pm 11$ & $117 \pm 14$ & $65.0 \pm 7.7+$ & $68.9 \pm 13^{\circ}$ \\
\hline Insulin (pmol/L) & $280 \pm 43$ & $344 \pm 43$ & $136 \pm 22 \ddagger$ & $230 \pm 43 \S$ \\
\hline Oxygen consumption $(\mu \mathrm{mol} / \mathrm{min})$ & $562 \pm 36$ & $642 \pm 37$ & $587 \pm 41$ & $594 \pm 39$ \\
\hline $\mathrm{CO}_{2}$ production $(\mu \mathrm{mol} / \mathrm{min})$ & $600 \pm 94$ & $543 \pm 69$ & $451 \pm 70$ & $493 \pm 71$ \\
\hline Umbilical blood flow (mL/min) & $653 \pm 61$ & $630 \pm 57$ & $661 \pm 57$ & $634 \pm 54$ \\
\hline
\end{tabular}

* Significance testing was done by three-way ANOVA and single degree of freedom cell means orthogonal contrasts.

$\dagger p<0.05$, fed during glucose vs fed preglucose.

$\ddagger p<0.05$, fasted preglucose $v$ s fed preglucose.

$\S p<0.05$, fasted during glucose $v s$ fasted preglucose. 

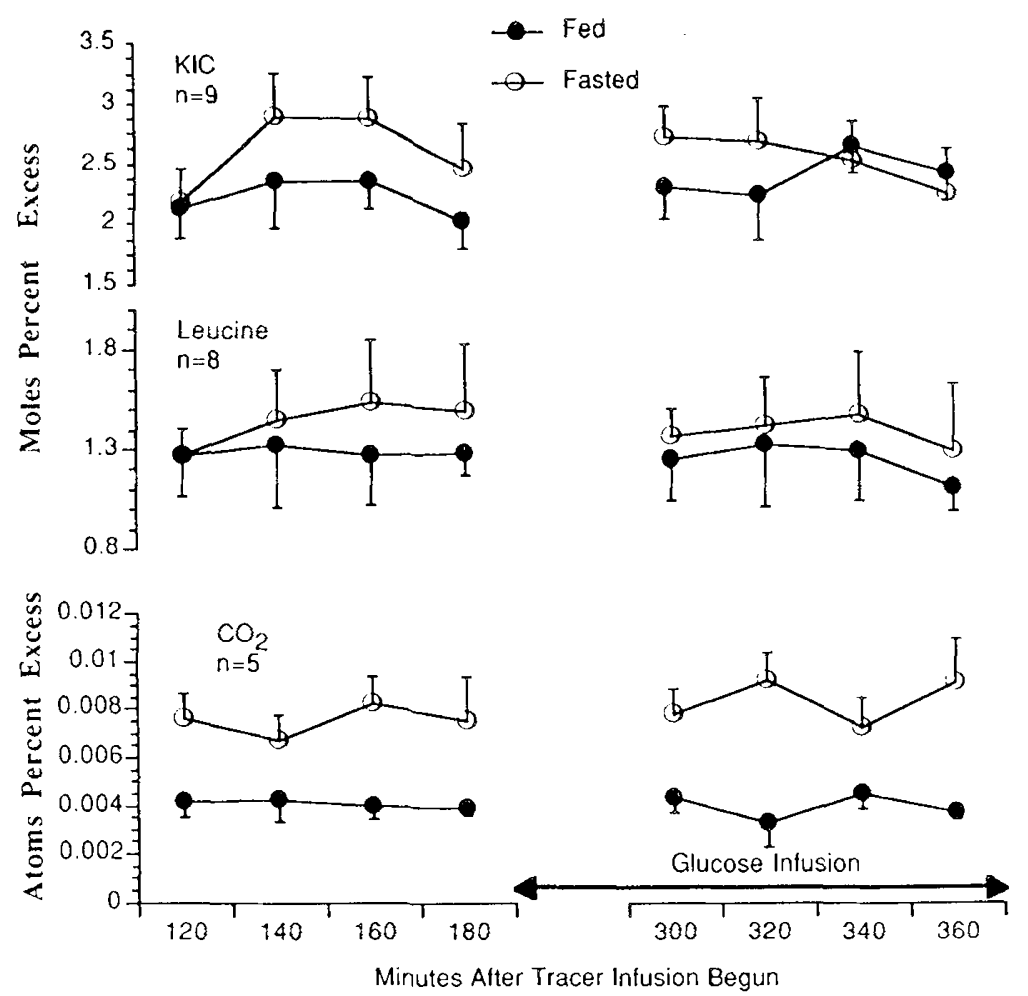

Fig. 4. Isotopic enrichments of $\mathrm{CO}_{2}$, leucine, and $\mathrm{KIC}$ achieved during the study. Samples obtained at $120,140,160$, and 180 min were before beginning the glucose infusion. Samples obtained at 300,320,340, and 360 min were during the glucose infusion. Data are presented as mean \pm SEM.

Table 2. Parameters of leucine flux in the ovine fetus (mean $\pm S E M)^{*}$

\begin{tabular}{|c|c|c|c|c|c|}
\hline & \multicolumn{2}{|c|}{ Fed } & \multicolumn{2}{|c|}{ Fasted } & \multirow[b]{2}{*}{$n$} \\
\hline & Preglucose & During glucose & Preglucose & During glucose & \\
\hline Fetal leucine uptake & $14 \pm 0.6$ & $8.7 \pm 1.0$ & $9.3 \pm 0.8$ & $11 \pm 0.9$ & 9 \\
\hline Fetal KIC uptake & $0.6 \pm 0.6$ & $0.54 \pm 0.2$ & $1.3 \pm 0.3 \dagger$ & $1.0 \pm 0.5$ & 9 \\
\hline Carbon flux & $30 \pm 3.0$ & $26 \pm 2.8$ & $28 \pm 3.2$ & $27 \pm 3.0$ & 9 \\
\hline Oxidation & $5.1 \pm 1.2$ & $4.7 \pm 0.8$ & $13.7 \pm 2.5 \dagger$ & $7.4 \pm 3.1 \ddagger$ & 5 \\
\hline $\begin{array}{l}\text { Leucine derived from protein break- } \\
\text { down }\end{array}$ & $16.6 \pm 7.2$ & $15.1 \pm 5.1$ & $22 \pm 6.6$ & $16.5 \pm 5.7$ & 5 \\
\hline Nonoxidative disposal of leucine & $24.4 \pm 6.0$ & $22 \pm 3.0 \S$ & $17.5 \pm 3.0 \dagger$ & $20.4 \pm 2.0$ & 5 \\
\hline
\end{tabular}

* Four sets of oxidation data were excluded from analysis because of technical difficulties with the samples. Nitrogen flux was determined in eight animals. Breakdown data were estimated only for those animals for which synthesis data were also available. All data are expressed as $\mu \mathrm{mol} / \mathrm{min}$. Significance testing was done by three-way ANOVA and single degree of freedom cell means orthogonal contrasts.

$\dagger p<0.05$, fasted preglucose $v s$ fed preglucose.

$\$ p<0.05$, fasted during glucose $v$ s fasted preglucose.

$\S p<0.05$, fed during glucose $v s$ fed preglucose.

Our data show that the reate of leucine carbon flux and the fetal uptake of leucine are unchanged during maternal fasting. In the presence of substantially reduced fetal umbilical glucose uptake and decreased fetal insulin concentrations, oxidation of leucine does increase, at the expense of nonoxidative disposal. The net result during fasting of the ewe is a reduction in fetal nitrogen accretion. In fact, our data suggest the possibility of negative nitrogen balance during states of reduced fetal energy substrate availability (Fig. 6).

Leucine nitrogen flux exceeds carbon flux, but to a lesser extent than has been seen in other species studied postnatally. Our previous data have demonstrated that during fasting of the ewe the arteriovenous differences for the BCAA across the fetal hindlimb increased substantially, whereas the balance of alanine and glutamine, transmination products of the BCAA, became negative (17). There appeared to be an increased entry of BCAA into the fetal hindlimb, resulting in a significant efflux of transamination products. This suggests that, during fasting of the ewe, carcass (skeletal muscle) becomes the predominant tissue catabolizing the BCAA. It has been shown in vitro (18) and in vivo (19) that the rate of efflux of alanine from skeletal muscle cells is dependent on the availability of BCAA (acting as N donor) and pyruvate (acting as $\mathrm{N}$ acceptor).

A decrease in transamination with fasting is a similar response to that which has been seen in postnatal animals. Forearm studies in humans (20) and whole body studies in dogs (21) have demonstrated reduced rates of transamination and flux during fasting. However, the fetal fasting model differs in that the fetus continues to receive metabolizable energy substrate during maternal fasting (albeit reduced in amount) and maintains a large and unchanged total amino acid and leucine intake.

Our data also suggest that leucine oxidation can be decreased during the fasted state by infusion of exogenous glucose into the fetus. This effect was not observed in the fed state. Rates of leucine oxidation were directly correlated with arterial leucine concentration. The arterial KIC concentration, an activator of 


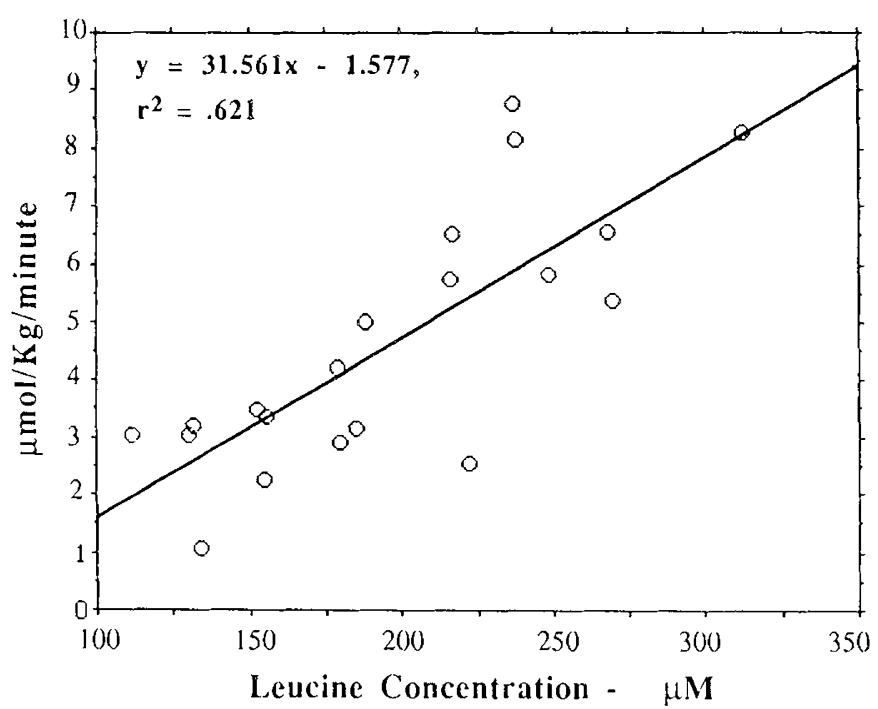

Fig. 5. The relationship between fetal leucine oxidation and plasma leucine concentration is depicted. The leucine oxidation rates are normalized to the fetal weight at the time of sacrifice. Five animals were studied, each in four states.

Table 3. Whole blood KIC enrichments in the fetal umbilical artery and umbilical vein (mean $\pm S E M, n=9$ )*

\begin{tabular}{cccccc}
\hline & \multicolumn{2}{c}{ Fed } & & \multicolumn{2}{c}{ Fasted } \\
\cline { 2 - 3 } \cline { 5 - 6 } & $\begin{array}{c}\text { Pre- } \\
\text { glucose }\end{array}$ & $\begin{array}{c}\text { During } \\
\text { glucose }\end{array}$ & & $\begin{array}{c}\text { Pre- } \\
\text { glucose }\end{array}$ & $\begin{array}{c}\text { During } \\
\text { glucose }\end{array}$ \\
\hline $\begin{array}{c}\text { Umbilical } \\
\text { artery } \\
\text { Umbilical } \\
\text { vein }\end{array}$ & $2.68 \pm 0.23$ & $2.12 \pm 0.23$ & $1.35 \pm 0.41$ & $1.87 \pm 0.30$ \\
\hline
\end{tabular}

* The data in each state were analyzed by paired $t$ test, and no statistically significant differences between the arterial and venous enrichments were found.

BCAA dehydrogenase, is also strongly correlated with leucine concentration. It is possible that, because of the higher leucine and KIC concentrations in the fetus as compared with the mother, the oxidation rate in the fed state represents a minimal rate that can not be diminished despite the provision of alternative oxidative substrate. This hypothesis remains to be proven.

Our estimates of turnover and oxidation are somewhat higher than previous investigators have found. This is not surprising in that our flux estimates are calculated from the plasma KIC enrichment rather than plasma leucine enrichment. Comparing our disposal rates with those of Van Veen et al. (22) (which were calculated using leucine $\mathrm{sp}$ act) on a weight-specific basis yields a ratio of approximately 0.7 . This is the expected ratio of KIC:leucine isotopic enrichment or sp act in a wide variety of models, including studies of fetal (23) and 1- to 2-wk-old lambs (24). In postnatal animals plasma KIC is thought to represent the intracellular leucine enrichment and thus be a more appropriate denominator (than plasma leucine enrichment) for the estimation of leucine oxidation and leucine derived from protein breakdown. This is most likely the case when all plasma KIC is derived from intracellular leucine. In the fetus, however, KIC also enters the fetal plasma pool across the placenta. It is not known whether this KIC is the result of deamination within the placenta of maternal or fetal leucine, or whether in fact it comes directly from the maternal leucine carbon pool. However, placental deamination of maternal leucine, followed by fetal uptake, would result in a dilution of the umbilical venous KIC enrichment relative to the arterial enrichment. Our data show no difference in the relative enrichment. These data are in agreement with those recently published by Loy et al. (25). This suggests that KIC taken up by the fetus is derived primarily from the fetal pool.

Oxidation and turnover will be overestimated to the extent to which unlabeled KIC entering fetal plasma causes dilution of the fetal plasma KIC pool. On the other hand, use of leucine as the denominator will underestimate oxidation and turnover to the extent that plasma leucine enrichment overestimates intracellular enrichment. It seems likely that true oxidation rates lie between those calculated using leucine enrichment as the denominator and those using $\mathrm{KIC}$ enrichment.

In addition to these theoretical concerns, it must be acknowledged that accurate determinations of leucine oxidation and leucine uptake are dependent upon precise determinations of umbilical blood flow and substrate concentration. The determination of oxidation requires the determination of fetal $\mathrm{CO}_{2}$ production. This is especially demanding, inasmuch as the coefficient of extraction for $\mathrm{CO}_{2}$ is $5-10 \%$ of the arterial concentration. Because of the errors inherent in each of these separate measurements, which must then be multiplied to obtain the rates of leucine oxidation or fetal leucine uptake, these estimates have a greater inherent error than do the flux measurements. This also applies to all estimates that derive from these parameters (i.e. synthesis, breakdown, and deamination).

In summary, our data confirm previous findings that leucine oxidation increases during fasting and suggest that the excess leucine for oxidation derives mainly from diminished flux of leucine into protein, rather than increased protein breakdown. The increased rate of leucine oxidation may exceed the rate of fetal uptake, resulting in a net negative leucine balance. By inference, this would lead to a net negative protein accretion rate, although it has not been definitively established that oxidation of other amino acids increases to the same extent as does leucine oxidation. Finally, the data suggest that provision of exogenous glucose can diminish the rate of leucine oxidation and improve leucine balance in the fasted state.

Acknowledgments. The authors thank the Diabetes Research and Training Center Radioimmunoassay Core facility for the insulin assays and Dr. Helen Morehead and Diane Habash for assistance with the experimental work.

Table 4. Parameters of leucine nitrogen flux in the ovine fetus (mean $\pm S E M)^{*}$

\begin{tabular}{cccccc}
\hline & \multicolumn{3}{c}{ Fed } & \multicolumn{2}{c}{ Fasted } \\
\cline { 2 - 6 } & $\begin{array}{c}\text { Pre- } \\
\text { glucose }\end{array}$ & $\begin{array}{c}\text { During } \\
\text { glucose }\end{array}$ & $\begin{array}{c}\text { Pre- } \\
\text { glucose }\end{array}$ & $\begin{array}{c}\text { During } \\
\text { glucose }\end{array}$ \\
\hline Nitrogen flux & $56 \pm 7$ & $55 \pm 7$ & $49 \pm 5$ & $51 \pm 6$ & 8 \\
Deamination & $51 \pm 7$ & $42 \pm 8$ & $38 \pm 7$ & $42 \pm 7$ & 5 \\
Reamination & $27 \pm 5$ & $21 \pm 9$ & $18 \pm 4 \dagger$ & $22 \pm 5$ & 8 \\
\hline
\end{tabular}

* Nitrogen flux rates were determined in eight animals. Deamination rates were determined in the five animals for which oxidation data were available. All data are expressed as $\mu \mathrm{mol} / \mathrm{min}$. Significance testing was done by three-way ANOVA and single degree of freedom cell means orthogonal contrasts.

$\dagger p<0.05$, fasted preglucose $v s$ fed preglucose. 


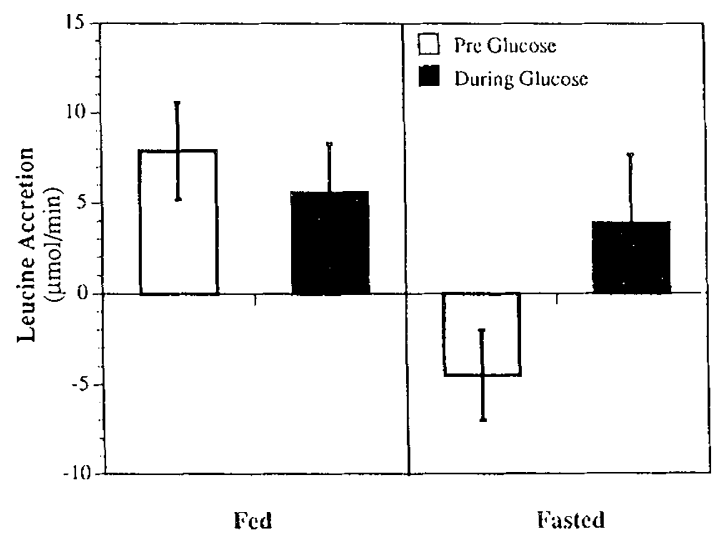

Fig. 6. The estimated rates of fetal carcass leucine accretion are depicted. Carcass accretion was calculated as the difference between leucine derived from protein breakdown and nonoxidative leucine disposal. Data are presented as mean $\pm \mathrm{SEM}, n=5$.

\section{REFERENCES}

1. Schreiner R, Lemons J, Gresham E 1981 Metabolic and hormonal response to chronic maternal fasting in the ewe. Ann Nutr Metab 25:38-47

2. Lemons J, Schreiner RL 1983 Amino acid metabolism in the ovine fetus. Am J Physiol 244:E459-E466

3. Lemons J, Liechty E 1987 Nitrogen flux across ovine maternal and fetal hindquarters during fasting. J Dev Physiol 9:151-158

4. Lemons J, Adcock E, Jones M, Naughton M, Meschia G, Battaglia F 1976 Umbilical uptake of amino acids in the unstressed fetal lamb. J Clin Invest 58:1428-1434

5. Livesay G, Edwards W 1985 Quantification of branched chain alphaketoacid quinoxalinols: importance of excluding oxygen during derivatization. J Chromatogr 37:98-102

6. Douglas AR, Jones NL, Reed JW 1988 Calculation of whole blood CO content. J Appl Physiol 65:473-477

7. Read W, Read M, Rennie M, Griggs R, Halliday D 1984 Preparation of $\mathrm{CO}_{2}$ from blood and protein bound amino acid carboxyl groups for quantification and ${ }^{13} \mathrm{C}$-isotope measurements. Biomed Mass Spectrom 11:348-352

8. Mathews D, Ben-Galim E, Bier D 1979 Determination of stable isotopic enrichment in individual plasma amino acids by chemical ionization mass spectrometry. Anal Chem 51:80-84

9. Rosenblatt J, Wolfe RR 1988 Calculation of substrate flux using stable isotopes. Am J Physiol 254:E526-E531

10. Ford $\mathrm{G}$, Cheng $\mathrm{K}$, Halliday D 1985 Analysis of $\left(1-{ }^{13} \mathrm{C}\right)$ leucine and $\left({ }^{13} \mathrm{C}\right) \mathrm{KIC}$ in plasma by capillary gas chromatography/mass spectrometry in protein turnover studies. Biomed Mass Spectrom 12:432

11. Meschia G, Cotter J, Makowski E, Barron D 1966 Simultaneous measurement of uterine and umbilical blood flows and oxygen uptakes. Q J Exp Physiol $52: 1-18$

12. Mathews DE, Bier DM, Rennie MJ, Edwards RHT, Haliday D, Millward DJ, Clugston GA 1981 Regulation of leucine metabolism in man: a stable isotope study. Science 214:1129-1131

13. Horber F, Horber-Feyder C 1989 Plasma reciprocal pool specific activity predicts that of intracellular free leucine for protein synthesis. Am J Physiol 257:E385-399

14. Van Veen L, Hay W, Battaglia F, Meschia G 1984 Fetal $\mathrm{CO}_{2}$ kinetics. J Dev Physiol 6:359-365

15. Wolfe R, Shaw J, Nadel E, Wolfe M 1984 Effect of substrate intake and physiological state on background ${ }^{13} \mathrm{CO}_{2}$ enrichment. J Appl Physiol 56:230234

16. Hocking RR 1985 The Analysis of Linear Models. Brooks/Cole Publishing Company, Monterrey, CA, pp 90-92

17. Liechty E, Polak M, Lemons J 1987 Branched chain amino acid carbon and nitrogen arteriovenous concentration differences across the ovine fetal hindlimb. Pediatr Res 21:44-48

18. Chang T, Goldberg AL 1978 The origin of alanine produced in skeletal muscle. J Biol Chem 253:3677-3684

19. Haymond M, Miles J 1982 Branched chain amino acids as a major source of alanine nitrogen in man. Diabetes 31:86

20. Cheng KN, Dworzak F, Ford GC, Rennie MJ, Halliday D 1985 Direct determination of leucine metabolism and protein breakdown in humans using $\mathrm{L}-\left[\mathrm{I}-{ }^{13} \mathrm{C},{ }^{15} \mathrm{~N}\right]$ leucine and the forearm model. Eur J Clin Invest 15:349354

21. Nissen S, Haymond M 1981 Effects of fasting on flux and interconversion of leucine and alpha-ketoisocaproate in vivo. Am J Physiol 241:E72-E75

22. Van Veen L, Battaglia F, Meschia G 1987 Leucine disposal and oxidation rates in the fetal lamb. Metabolism 36:48-53

23. Loy G, Quick AJ, Teng C, Hay WJ, Fennessey P 1990 Versatile stable isotope technique for the measurement of amino acids and keto acids: comparison with radioactive isotope and its use in measuring in vivo disposal rates. Anal Biochem 185:1-9

24. Oddy V, Lindsay D, Barker P, Northrop A 1987 Effect of insulin on hind-limb and whole body leucine and protein metabolism in fed and fasted lambs. Br J Nutr 58:437-452

25. Loy G, Quick AJ, Hay WJ, Meschia G, Battaglia F, Fennessey P 1990 Fetoplacental deamination and decarboxylation of leucine. Am J Physiol 259:E492--E497 